\title{
Development and quality assessment of a turbid carrot-orange juice blend processed by UV-C light assisted by mild heat and addition of Yerba Mate (Ilex paraguariensis) extract
}

\author{
M. Ferrario, M. Schenk, M. García Carrillo, S. Guerrero* \\ Departamento de Industrias, Facultad de Ciencias Exactas y Naturales, Universidad de Buenos Aires, Ciudad Universitaria, (1428) C.A.B.A., Argentina \\ Consejo Nacional de Investigaciones Científicas y Técnicas de la República Argentina, Argentina
}

\section{A R T I C L E I N F O}

\section{Keywords:}

UV-C light

Mild heat

Yerba mate

Juice blend

\begin{abstract}
A B S T R A C T
Carrot-orange juice processed by UV-C $\left(10.6 \mathrm{~kJ} / \mathrm{m}^{2}\right)$ assisted with mild heat $\left(\mathrm{H}, 50{ }^{\circ} \mathrm{C}\right)$ and yerba mate addition (E) was obtained. UV-C/H + E treated juice was examined for native flora, polyphenol content (PC), total antioxidant activity (TAA), colour, turbidity, ${ }^{\circ} \mathrm{Brix}$ and $\mathrm{pH}$ along storage $\left(4{ }^{\circ} \mathrm{C}\right)$. Consumer profiling studies were performed. UV-C/H + E provoked 2.6-5.7 native flora log reductions, preventing from recovery during 24 daystorage. The UV-C/H + E juice exhibited a significant increase in PC $(720.2 \mu \mathrm{g} / \mathrm{mL})$ and TAA $(5.5 \mathrm{mg} / \mathrm{mL})$ compared to untreated $(\mathrm{PC}=205.0 \mu \mathrm{g} / \mathrm{mL} / \mathrm{TAA}=0.7 \mathrm{mg} / \mathrm{mL})$ and single treated juices $(\mathrm{PC}=302.1-408.0 \mu \mathrm{g} /$ $\mathrm{mL} / \mathrm{TAA}=0.7-2.4 \mathrm{mg} / \mathrm{mL}$ ), remaining constant throughout storage. UV-C/H $+\mathrm{E}$ juice exhibited scarce changes in colour. Nevertheless, increases in ${ }^{\circ}$ Brix and turbidity were observed compared to single treatments. A cluster sensory analysis revealed that one group showed a marked interest in UVC/H + E beverages with herbal taste and strong aroma. CATA question revealed that some improvements should be introduced in order to satisfy the consumers' ideally beverage.
\end{abstract}

\section{Introduction}

The development of novel fruit and vegetable juices and beverages, enriched with bioactive compounds, has acquired during the last decade high relevance and growing interest due to their potential health benefits. These types of premium products currently have reshaped food industry, representing an important and constantly increasing portion of the global functional food markets (Leatherhead Food Research, 2013). Accordingly, with this trend, consumers demand more natural and healthy drinks, less heavily preserved and less reliant on synthetic additives (Mathews, 2006). Although conventional thermal processing, which generally involves pasteurization at temperatures between $85^{\circ} \mathrm{C}$ and $95^{\circ} \mathrm{C}$ for a few minutes or seconds, ensures safety and extends shelf life of juices, it often leads to detrimental changes in sensory and nutritional qualities of a given product, making such alternative unviable to preserve natural fresh-like juices (Cortés, Esteve, \& Frígola, 2008; Seljåsen et al., 2013).

A wide range of intervention technologies has emerged for alternative processing of fruit and vegetable juices. Among novel technologies, UV-C light has shown increasing potential for freshly squeezed juices disinfection. It encompasses the UV spectrum range from 200 to $280 \mathrm{~nm}$, being lethal to a large variety of microorganisms, without generating chemical residues, and being low-cost and energy efficient (Baysal, Molva, \& Unluturk, 2013). Exposure to UV light results in the cross-linking of neighboring pyrimidine nucleotide bases in the same deoxyribonucleic acid (DNA) strand, eventually causing cell death (García Carrillo, Ferrario, \& Guerrero, 2017a). UV-C pasteurization is affected by many different factors such as UV light source choice, reactor design, flow rate, type of liquid, viscosity, density, UV-C light absorptivity, presence of soluble and insoluble solids, and particle size (Koutchma, 2009). Therefore, until recently, the implementation of UV$\mathrm{C}$ as a decontamination technique has been limited to clear or transparent liquid foods or superficial treatments.

To overcome UV-C light limitations, combined processes under hurdle approach have been proposed, such as the application of UV light with other non-thermal technologies, or traditional ones, such as the use of heat or addition of chemicals and preservatives (Char, Guerrero, \& Alzamora, 2010; Guerrero, Alzamora, \& Ferrario, 2016; Schenk, García Loredo, Raffellini, Alzamora, \& Guerrero, 2012; Shah, Shamsudin, Abdul Rahman, \& Adzahan, 2016). In this way, it may be

\footnotetext{
* Corresponding author at: Departamento de Industrias, Facultad de Ciencias Exactas y Naturales, Universidad de Buenos Aires, Ciudad Universitaria, (1428) C.A.B.A., Argentina.

E-mail addresses: sguerrero@di.fcen.uba.ar (M. Ferrario), sguerrero@di.fcen.uba.ar (S. Guerrero).
} 
possible to find an answer to consumer demands for healthier and tasty foods. According to this approach, it is necessary to apply balanced hurdles, ensuring product safety and stability, achieving a hostile environment to inhibit microbial growth, shorten the survival or killing them, while not damaging the product's sensory and nutritional properties (Guerrero et al., 2016; Guerrero, Ferrario, Schenk, \& Garcia Carrillo, 2017). Lethality of combined treatments can result from an additive or synergistic effect. Synergy may arise when applied inactivation strategies act on the same cell target, increasing the chances of irreversible damage, or when they act on different sites, causing sublethal damage in several cell areas, enhancing their overall lethal potential (Guerrero et al., 2017; Ross, Griffiths, Mittal, \& Deeth, 2003).

In particular, the use of UV-C with the assistance of mild heat has been successfully applied for decontamination of juices and beverages. Gayán, Serrano, Monfort, Álvarez, and Condón (2012) achieved more than 5 log-cycles of Escherichia coli inactivation without affecting the $\mathrm{pH}$, acidity, total soluble solids, and colour in orange juice treated with UV-C (23.7 J/mL) and heat $\left(55^{\circ} \mathrm{C}, 3.6 \mathrm{~min}\right)$. Tan (2012) observed 5 logreductions of Listeria innocua in green guava juice treated by UV-C $\left(0.035 \mathrm{~kJ} / \mathrm{m}^{2}\right)$ followed by mild heat treatment $\left(55^{\circ} \mathrm{C}, 60 \mathrm{~s}\right)$ as well as the juice retained acceptable physicochemical properties. In addition, more than $5 \log$ - reductions of relevant strains such as Escherichia coli and Pseudomonas fluorescens, and an important reduction of $4.2 \mathrm{log}$ cycles of Saccharomyces cerevisiae were obtained in a turbid carrot-orange juice blend treated with UV-C light $\left(10.6 \mathrm{~kJ} / \mathrm{m}^{2}, 2.0 \mathrm{~J} / \mathrm{mL}\right)$ assisted by mild heat $\left(50^{\circ} \mathrm{C}, 15 \mathrm{~min}\right.$ ) (García Carrillo et al., 2017a).

Blending is one of the best methods to improve the nutritional quality of a resultant beverage, depending on the kind and quality of fruits and vegetables used (De Carvalho, Maia, \& De Figueredo, 2007). In particular, carrots are a rich source of carotenoids, polyphenols and vitamins. Multiple health benefits have been attributed to carrot consumption, encompassing antioxidant, anticarcinogenic, immunopotentiator (Dias, 2012), anti-diabetic, cholesterol and cardiovascular disease lowering and anti-hypertensive (Chau, Chen, \& Lee, 2004). A permanent increase of carrot juice consumption has been reported in many countries (Jan and Masih, 2012). Moreover, orange is the predominant juice manufactured by the beverage processing industry all around the world. It represents a substantial source of vitamin C (Polydera, Stoforos, \& Taoukis, 2003), which contributes to cancer prevention (Dias, 2012).

Plant-based beverages are gaining popularity among consumers because of the "green" and "natural" message associated to them. Yerba mate (Ilex paraguariensis A., St Hil.) or mate tea is an infusion widely consumed in some South American countries. It has been largely studied due to multiple properties attributed to its phenolic compounds like antioxidant, anti-inflammatory, central nervous system stimulant, anti-rheumatic, diuretic and antimicrobial (Burris, Higginbotham, \& Neal Stewart, 2015). These activities have been linked to the significant amount of phenolic compounds found in yerba mate leaves (Tamasi, Filip, Ferraro, \& Calviño, 2007). Yerba mate is gaining rapid introduction into the world market, either as tea itself or as ingredient in formulated foods or dietary supplements, representing a novel alternative of giving an added value to a given food product (Burris et al., 2015).

The aim of the present work was to develop a carrot-orange functional beverage processed by UV-C light assisted by mild heat, and enriched with a yerba mate extract, for the purpose of preserving as well as improving its nutritional quality. Evolution of native flora, total polyphenol content, antioxidant activity, colour, $\mathrm{pH}$, ${ }^{\circ} \mathrm{Brix}$ and turbidity were assessed along refrigerated storage on single and combined treatments. Moreover, a field test was conducted in order to evaluate overall acceptability of the product. Additionally, a check-all-that apply (CATA) question was performed to analyze which sensory attributes better described the processed juices and determine how much these samples differed from an ideal beverage.

\section{Materials and methods}

\subsection{Carrot-orange juice blend preparation}

Carrots and oranges were purchased in a local market and immediately refrigerated until use (maximum 1 day). Whole fruits were disinfected by immersion in a $1 \% \mathrm{v} / \mathrm{v}$ sodium hypochlorite solution during $5 \mathrm{~min}$. They were carefully rinsed with sterilized water and gently dried with a sterile cloth. Finally, they were exposed to UV-light during $10 \mathrm{~min}$ for superficial decontamination. This last step was omitted in the case of obtaining juice for native flora determination in order to increase the indigenous microbial load in the fruits.

Fresh carrot juice was manually obtained under aseptic conditions by pressing carrots (Daucus carota, var. Chantenay). A household juicer (Ju655, Moulinex, China) was sanitized with 70\% (v/v) ethanol and exposed to UV-C for $10 \mathrm{~min}$. Similarly, fresh orange juice (Citrus sinensis, var. Valencia) was obtained by using a household squeezer (Arno, São Paulo, Brazil). Juices were filtered with a double sterile muslin cloth (carrot juice) or centrifuged (orange juice, $157 \mathrm{~g}, 20^{\circ} \mathrm{C}$, $10 \mathrm{~min}$ ) in order to reduce pulp amounts. Both juices were subsequently mixed to obtain a 50:50 ratio (v/v) juice blend, $\mathrm{pH} 5.0$ adjusted by citric acid. After treatment, the blend was collected in amber glass bottles and stored at $-80^{\circ} \mathrm{C}$ until use.

\subsection{Yerba mate extracts obtainability}

Yerba mate (YM) dried-aged canchada (dried and aged leaves) gently provided by La Cachuera (Apóstoles, Misiones, Argentina) was used. Yerba mate leaves $(20 \mathrm{~g})$ were coarsely ground, mixed with $150 \mathrm{~mL}$ pure ethanol and subjected to two successive extractions assisted by US ( $\left.600 \mathrm{~W}, 20 \mathrm{kHz}, 95.2 \mu \mathrm{m}, 25^{\circ} \mathrm{C}, 10 \mathrm{~min}\right)$. US-assisted extractions were carried out in a $600 \mathrm{~mL}$-double wall cylindrical vessel connected to a thermostatically controlled water bath (HAAKE, Model Rotovisco RV12, Germany). Extracts were membrane filtered (pore: $0.45 \mu \mathrm{m}$ ), evaporated (rotary evaporator, $50{ }^{\circ} \mathrm{C}, 40 \mathrm{~min}$ ), resuspended in water and lyophilized ( $24 \mathrm{~h}$, Stokes model 21 , Philadelphia, USA).

\subsection{UV-C treatment}

The UV-C device consisted of two serially connected UV-C lamps (TUV-30 W, $253.7 \mathrm{~nm}$, Philips, The Netherlands), each one inside a $0.87 \mathrm{~m}$-long glass tube which leaves an annular flow space (outer diameter $=0.031 \mathrm{~m} ; \quad$ inner diameter $=0.024 \mathrm{~m}$, volume $=0.22 \mathrm{~L}$ ), working as an irradiation chamber (García Carrillo et al., 2017a). Inlet and outlet of juice to the chamber was carried out by autoclavable flexible hoses (Cole-Parmer, Masterflex, L/S 24, Illinois, USA), which discharged into a double jacket vessel, connected to the water bath to attain 20 or $50{ }^{\circ} \mathrm{C}$ in the vessel. UV-C performed at $20^{\circ} \mathrm{C}$ was considered as a single treatment (UV-C). UV-C assisted by mild heat $\left(50^{\circ} \mathrm{C}\right)$ corresponded to the combined treatment (UV-C/H). In addition, single thermal treatment $(\mathrm{H})$ was performed in the same way but with lamps turned off.

Before starting, UV-C lamps were turned on during $15 \mathrm{~min}$ in order to stabilize them and to sterilize the irradiation chamber. The obtained juice blend $(745 \mathrm{~mL})$ was added to the vessel and recirculated $(1.6 \mathrm{~L} /$ min, $15 \mathrm{~min}$ ) through the device using a peristaltic pump (CPX-400, Cole Parmer, Vernon Hills, Illinois, USA). All assays were carried out in triplicate. The UV-C dose emitted from the lamps was determined by using a radiometer (Melles Griot, 13 PEM 001 model, Boulder, Colorado, USA) and the chemical actinometrical pair iodure/iodate according to the method proposed by Rahn (1997) and adapted to a continuous flow operation (Char et al., 2010). UV-C dose obtained with the radiometer was calculated as the average of both lamps. The UV-C dose reported corresponded to the average of both methods employed.

Unprocessed juice with YM extract was considered as control-1; whereas, unprocessed juice without YM addition corresponded to 
control-2. UV-C at $50{ }^{\circ} \mathrm{C}$ with or without YM addition corresponded to $\mathrm{UV}-\mathrm{C} / \mathrm{H}+\mathrm{E}$ or $\mathrm{UV}-\mathrm{C} / \mathrm{H}$ samples, respectively. YM was added in a concentration of $0.004 \mathrm{~g} / \mathrm{mL}$.

\subsection{Native flora evolution}

For the native flora study, three independent samples treated or not (controls) by single UV-C and $\mathrm{H}$ and, combined UV-C/H and UV-C/ $\mathrm{H}+\mathrm{E}$ treatments were evaluated. Unprocessed juice with (control-1) and without YM extract (control-2) were used as two control samples in order to additionally evaluate any potential YM antimicrobial activity. Systems were poured into $10-\mathrm{mL}$ caramel flasks and stored under refrigeration conditions $\left(4 \pm 1{ }^{\circ} \mathrm{C}\right)$ for 24 days. Throughout storage, samples were taken at each preset time interval (24-72 h) for analysis of total aerobic mesophiles, yeast and moulds, and total coliforms. Total aerobic mesophilic population was determined in Plate Count Agar (PCA, $72 \mathrm{~h}$ at $37 \pm 1{ }^{\circ} \mathrm{C}$ ). Yeast and moulds population was cultured in Chloramphenicol Glucose Agar (CGA, 5 days at $25 \pm 1{ }^{\circ} \mathrm{C}$ ). Total coliforms population was determined in Violet Red Bile Agar (VRB, $48 \mathrm{~h}$ at $30 \pm 1{ }^{\circ} \mathrm{C}$ ). Plots of $\log \mathrm{N}$ versus treatment time were obtained.

\subsection{Physicochemical characterization of juices along storage}

Total phenolic content, total antioxidant activity, $\mathrm{pH}$, ${ }^{\circ} \mathrm{Brix}$, turbidity and colour of untreated or processed juice by single UV-C and $\mathrm{H}$ treatments or combined UV-C/H and UV-C/H + E treatments were assessed along refrigerated storage. Juice samples were aseptically dispensed into $10-\mathrm{mL}$ caramel flasks, and stored in the dark at $4 \pm 1{ }^{\circ} \mathrm{C}$ during 24 days. During storage, three flasks of each condition were taken at preset time intervals for analysis.

Turbidity was determined with a turbidimeter (LaMotte 2020we, Chestertown, Maryland, USA) using AMCO Primary Turbidity (100 NTU) and Formazin standards (4000 NTU). PH and ${ }^{\circ}$ Brix were measured with a pH meter (PerpHect pH/ISE model 310, Orion Research Inc., Beverly, USA) and a hand held refractometer (PR-101 Palette, ATAGO Co. LTD, Japan), respectively. Colour of juices was measured with a handheld tristimulus reflectance spectrocolorimeter (Minolta Co. Model CM-508-d, Osaka, Japan) by using a 1.4 measuring aperture with white and black background. Three (3) $\mathrm{mL}$ of sample were measured using illuminant $\mathrm{C}$ and $2^{\circ}$ standard observer angle. Before each measurement, the instrument was calibrated with a standard provided by the manufacturer. The CIE colour coordinates (X, Y, Z) and the components of the CIELAB space, L* (lightness), a* (green-red) and b* (blueyellow) were recorded.

Total phenolic content (PC) was determined using the FolinCiocalteu method (Singleton, Orthofer, Lamuela-Raventós, \& Lester, 1999). A calibration curve of Gallic acid (ranging from 0.0025 to $0.125 \mathrm{mg} / \mathrm{mL}$ ) was prepared. Sample concentrations were determined from the calibration curve $\left(y=13.2465 x+0.0518, R^{2}=0.99\right)$ and expressed as $\mathrm{mg}$ of Gallic acid equivalents per milliliter of the sample, GAE/mL. Briefly, $0.5 \mathrm{~mL}$ of juices samples, 100 times diluted in distilled water, was mixed with $2.5 \mathrm{~mL}$ of Folin-Ciocalteu phenol reagent $(10 \%$ $\mathrm{v} / \mathrm{v})$, followed by $2 \mathrm{~mL}$ of $\mathrm{Na}_{2} \mathrm{CO}_{3}(7.5 \% \mathrm{w} / \mathrm{v})$ addition. The reactive mixture was allowed to stand for $3 \mathrm{~h}$ in darkness, and the formation of blue colour, as indicator of PC, was quantified at $740 \mathrm{~nm}$ using a UV-VIS spectrophotometer (V-630, Jasco, Tokyo, Japan).

Total antioxidant activity (TAA) was evaluated using a colorimetric method based on the free radical scavenging sample capacity, which was evaluated using the 2,2-diphenyl-1-picrylhydrazyl (DPPH) stable radical (Merck, Billerica, MA USA) according to the methodology proposed by Gutiérrez, Char, Escalona, Chaves and Rodríguez (2015). Eighty (80) microliter of sample diluted 1500 times with methanol was mixed with $2200 \mu \mathrm{L}$ of DPPH $(0.02 \mathrm{~g} / \mathrm{L}$ in methanol). The reaction mixture was led to stand for $30 \mathrm{~min}$ at $25^{\circ} \mathrm{C}$ in the dark, and absorbance was measured at $515 \mathrm{~nm}$ using a UV-VIS spectrophotometer (V-630, Jasco, Tokyo, Japan). A calibration curve was obtained using Trolox
(Merck, Billerica, MA USA) as a standard, and the results determined from the calibration curve ( $\left.y=0.00084 x-0.0024, R^{2}=0.98\right)$, and expressed as Trolox equivalents ( $\mu$ g Trolox Eq/mL).

\subsection{Sensory studies}

There is currently an industrial pressure to develop alternative methods that skip the sensory panel training step, as well as gather sensory information directly from consumers. Several consumer profiling methodologies have recently increased their popularity for the evaluation of new products. According to this approach, two consumer profiling techniques, the check-all-that-apply (CATA) question and the consumer field test, were used in order to better describe juice samples. Eighty four (84) unpaid volunteers recruited from personnel and students of Buenos Aires University, aged between 25 and 55 years and selected as frequent consumers of yerba mate tea and juice, participated in the monadic tests. Each subject evaluated a 15-mL juice sample treated with UV-C/H and UV-C/H + E. Samples were presented to the panelists at common serving temperature $\left(5-7^{\circ} \mathrm{C}\right)$ in white plastic cups, and water was available for rinsing between samples. The evaluations were carried out in individual booths under white light (ISO 8589:1988). For each sample, consumers firstly determined overall acceptability and some relevant sensory attributes by a consumer field test. Finally, they also performed the profiling technique, check-allthat-apply (CATA) question, which evaluated which sensory attributes were mainly perceived in the different processed juices. Moreover, consumers were asked to check all those sensory attributes that they would assign to an ideal juice blend, in order to measure the relative deviation of the processed juice samples to this prototype (Lawless, 2013a).

A consumer field test form was designed according to general recommendations cited by Lawless and Heymann (2010) for this type of test. Firstly, all subjects were instructed to judge the general acceptability of each sample on a 9-point hedonic scale (1-dislike extremely; 9-like extremely) which was immediately followed by open-ended questions for liking or disliking with an appropriate "skip pattern". The skip pattern dropped to reasons for liking if the response was positive, and then probed any dislikes, and vice versa. Additionally, some juice attributes were evaluated by using 5-point scales, which corresponded to acceptability, intensity and/or adequacy of each attribute in the juice sample. In particular, herbal taste was evaluated in a short intensity scale with labeled ends (1: without herbal taste; 5 : very intense herbal taste). Similarly, bitterness was evaluated in a short intensity scale with labeled ends (1: not bitter to 5: extremely bitter). Juice's sour tasting, aroma and juice body were evaluated using just right (JAR) scales, labeled at the left end as "not sour enough", "too week aroma" or "without enough juice body"; at the right end as "extremely sour", "very intense aroma" or "with too much juice body", respectively, and "just right" in the middle of all scales. Previously to each session, each scale and all the terminology corresponding to the questionnaire were explained several times until panelists fully understood.

Regarding the CATA question, all panelists answered a questionnaire which consisted of sensory descriptors, which were generated in a preliminary round table session. The selected sensory descriptors were: pleasant colour, strong colour, natural taste, intense taste, artificial taste, orange taste, carrot taste, herbal taste, herbal aroma, fruity, not fruity, with aftertaste, cooked taste, too particulate, taste persistence, strange taste, strange aroma, pleasant juice body, astringent. Consumers were explained that they had to choose all the terms mentioned in the checklist that they considered appropriate to describe each drink (Lawless, 2013a). The CATA counts were totaled for each product and the resulting contingency table was used in subsequent analyses.

Additionally, panelists were asked to check all the non-sensory descriptors that they considered better described juice samples: would consume occasionally, would consume every day, refreshing, healthy and especially designed for healthy diets. The citation frequency of each term 
was recorded.

\subsection{Statistical analysis}

Multivariate analysis of variance (MANOVA) was applied to determine significant differences in PC, TAA, colour, $\mathrm{pH}$, ${ }^{\circ} \mathrm{Brix}$ and turbidity according to the factors "treatment", "time" and the interaction term, "treatment * time". Significance level was set at p $<0.05$. In the case of finding significant differences, post-hoc multiple comparisons among multivariate factors' means were performed by the Hotelling test based on the Bonferroni correction.

For the consumer field test, data from scales were analyzed by converting assigned positions into numbers. Results were reported as an average of the individual values. Responses corresponding to openended questions were collected and qualitatively analyzed by grouping common attributes described by the panelists into categories. An agglomerative hierarchical cluster analysis was carried out using weighted average linkage and Euclidean distance to find whether there was segmentation in the preference of consumers for the carrot-orange juice with YM addition (Lawless, 2013b). A principal component analysis (PCA) was applied to illustrate the association between scores obtained for the overall impression with the ones corresponding to the juice's attributes evaluation. The overall goodness of fit was measured by the cophenetic correlation coefficient (CCC) (Lawless, 2013b). An adequate fit for the cluster and PCA analyses is described by a CCC value close to 1 .

For the CATA question, a Friedman's test was carried out for each of the checked terms, in order to evaluate if this technique was able to detect differences among consumers regarding their samples' perception, considering sample and consumer as sources of variation. A Correspondence Analysis (CA) was performed from the frequency table, which contained all the responses regarding sensory descriptors included in the CATA question of UV-C/H, UV-C/H + E samples and the ideal beverage. Moreover, a $\chi^{2}$ test was conducted to compare the frequencies of non-sensory descriptors obtained from the CATA question of UV-C/H and UV-C/H + E samples.

Statistical analyses were carried out using InfoStat 2009 (InfoStat Group, FCA-UNC, Córdoba, Argentina).

\section{Results and discussion}

\subsection{Native flora}

The evolution of native flora (total aerobic mesophiles, yeast and moulds, and total coliforms) during refrigerated storage of combined UV-C/H at $50{ }^{\circ} \mathrm{C}$ with or without YM extract (UV-C/H + E) is shown in Fig. 1. Additionally, Fig. 1 illustrates the evolution of juices treated by single UV-C and $\mathrm{H}$, together with untreated (control-2) carrot-orange juice blend and untreated juice with yerba mate extract addition (control-1).

In the case of total aerobic mesophiles, untreated samples with or without YM extract addition (control-1 and control-2) exhibited an oscillatory behaviour characterized by an increase in population, exceeding the acceptable limit $\left(10^{7} \mathrm{CFU} / \mathrm{mL}\right)$ established by the Health Protection Agency, HPA (2009) by 13 days of refrigerated storage (Fig. 1a). Regarding yeast and mould population, there was a delay in their recovery for both control samples which was more pronounced in the case of control-1 ( $\sim 10$ days) compared to control-2 ( $\sim 7$ days), point from which both populations increased reaching 5 log cycles by the end of the storage (Fig. 1b). For total coliform population, both control samples exceeded, from the onset, the acceptable limit $\left(10^{4}\right.$ $\mathrm{CFU} / \mathrm{mL}$ ) recommended by HPA (2009) for Enterobacteriaceae, reaching up to $\sim 7$ log cycles by the end of storage (Fig. 1c). Therefore, YM extract addition did not prevent from native flora increase in untreated juice (control-1) along storage as it only scarcely extended the lag period for yeast and mould population. a

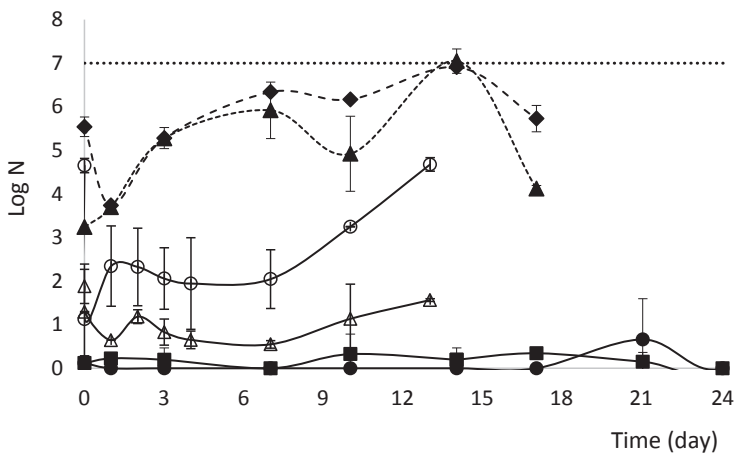

b

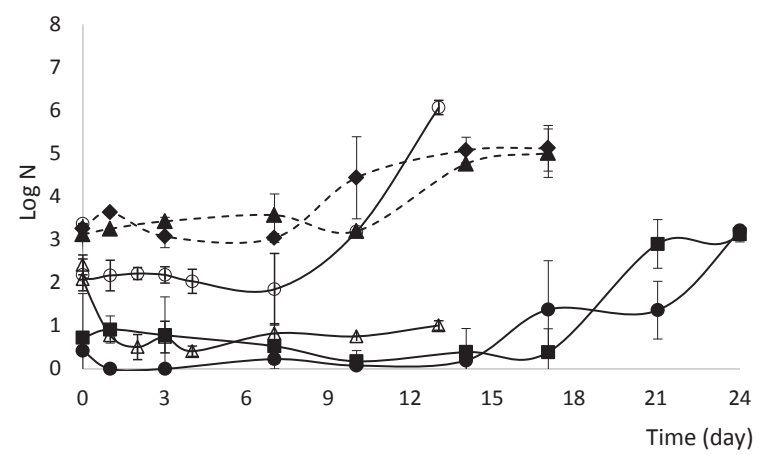

C

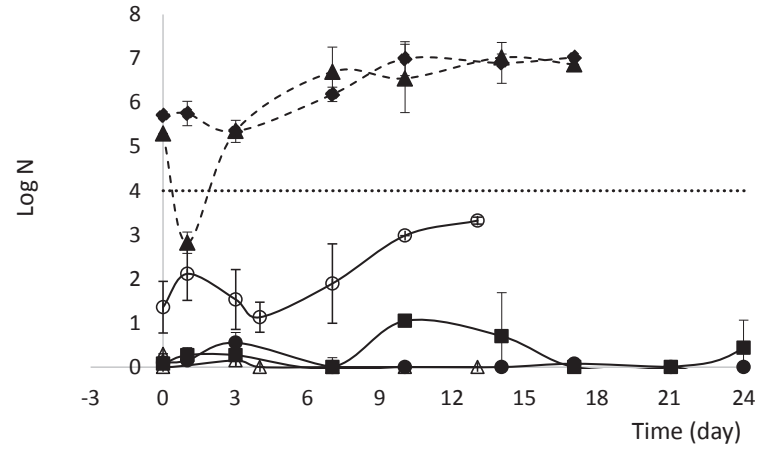

Fig. 1. Evolution of native flora in natural pressed carrot-orange juice blend stored at $4 \pm 1{ }^{\circ} \mathrm{C}$. Control $(-, \downarrow)$ or control with yerba mate extract $(-, \mathbf{\Lambda})$, and treated ( - ) by UV-C $(\mathrm{O}), \mathrm{H} 50^{\circ} \mathrm{C}(\Delta)$, combined UV-C/H $(\bullet)$ or UV-C/ $\mathrm{H}+\mathrm{E}(\boldsymbol{\square})$ of mesophilic aerobic population (a), yeasts and moulds (b), and total coliforms (c). Standard deviation (I).

With regards to single treatments, single UV-C $\left(10.6 \mathrm{~kJ} / \mathrm{m}^{2}\right) \mathrm{sig}$ nificantly reduced by $3.5,1.2$ and $0.3 \log$ cycles the initial total aerobic mesophilic, yeast and moulds, and coliforms populations, respectively, and prevented from their recovery during 7 days of refrigerated storage. The recommended limit for aerobic mesophilic population was not exceeded during 13 days of refrigerated storage (Fig. 1a). Yeast and moulds population increased at the end of storage up to 6 log cycles (Fig. 1b). Whereas, total coliforms did not exceed the limit $\left(10^{4} \mathrm{CFU} /\right.$ $\mathrm{mL}$ ) admitted for Enterobacteriaceae, determined by HPA (2009) during 13 days of refrigerated storage (Fig. 1c). Additionally, single $\mathrm{H}$ treatment only reduced between 0.3 and 0.5 log-cycles in aerobic mesophilic and, yeast and moulds populations (Fig. 1), which increased during refrigerated storage but into a lesser extent compared to control samples, suggesting that $\mathrm{H}$ treatment induced sub-lethal damage that could make native flora more sensitive to the subsequent refrigeration conditions (García Carrillo, Ferrario, \& Guerrero, 2017b). The initial population of total coliform was eliminated with $\mathrm{H}$ treatment and no recovery was observed during the refrigerated storage.

Combined UV-C/H and UV-C/H + E provoked 5.5 (99.0\% reduction), 5.7 (99.0\% reduction) and $2.6-2.9$ (21\% reduction) log reductions of aerobic mesophilic microorganisms, total coliforms and, yeasts 
and moulds, respectively (Fig. 1). Moreover, aerobic mesophilic and total coliform populations remained constant and almost non-detectable throughout the whole storage ( 24 days). Whereas, yeasts and moulds began to grow by the 17th day, observing 3.1-3.2 log cycles by the end of storage. Thus, the combination UV-C/H was successful in extending juice shelf life for 24 days of refrigerated storage, while YM addition did not improve native flora inactivation.

In agreement with this study, Pala and Toklucu (2013), studied the inactivation of total aerobic and yeast and moulds counts in orange juice (pH: $\left.4.0,11.6{ }^{\circ} \mathrm{Brix}\right)$ after exposure to UV-C light $(0.0-48.1 \mathrm{~kJ} / \mathrm{L})$. They observed that total aerobic load was reduced by 2.96 log cycles (91\%) after UV-C treatment. In addition, they reported that only up to $0.52 \log (20.2 \%)$ reductions in the initial yeast and moulds load were achieved after UV-C exposure. They attributed the highest sensitivity of bacteria to UV-C to the higher amount of thymine bases, main target of UV-C, compared to yeasts and moulds. These authors also evaluated the evolution of native flora along refrigerated storage $\left(4^{\circ} \mathrm{C}\right)$, and observed a $0.98 \mathrm{log}$ increase of yeasts and moulds population by 15 days of storage, and a fast increase of $2.81 \mathrm{log}$ of total aerobic counts during storage. In addition, Chia, Rosnah, Noranizan, and Wan (2012) observed that UV-irradiated $\left(0.53 \mathrm{~kJ} / \mathrm{m}^{2}\right)$ pineapple juice $\left(\mathrm{pH}: 3.9 ; 13.5^{\circ}\right.$ Brix) achieved a shelf life up to 7 weeks along refrigerated storage $\left(4^{\circ} \mathrm{C}\right)$; in contrast to the 1 week shelf life of untreated juice. Feng, Ghafoor, Seo, Yang and Park (2013) examined the effect of UV-C $(2.7 \mathrm{~kJ} / \mathrm{L})$ on the evolution of native flora in watermelon juice ( $\mathrm{pH}: 5.3$; $9.5^{\circ}$ Brix), which was reduced by $1 \log$ the total aerobic population in treated juice. However, total aerobes were able to recover by $2 \log$ cycles after 13 days of storage. While, coliforms were immediately reduced by $\sim 3 \log$ cycles in treated samples respect to the untreated one, and remained constant during storage for up to 13 days. In the case of yeasts and moulds, UV-C prevented from recovery up to 13 days of storage.

\subsection{Physicochemical characterization of juices along storage}

\subsubsection{Polyphenol content and antioxidant activity}

Fig. 2 illustrates total PC and TAA corresponding to untreated carrot-orange juice and processed by single UV-C and $\mathrm{H}$, and combined $\mathrm{UV}-\mathrm{C} / \mathrm{H}$ and $\mathrm{UV}-\mathrm{C} / \mathrm{H}+\mathrm{E}$ treatments during refrigerated storage $\left(4 \pm 1{ }^{\circ} \mathrm{C}\right)$.

UV-C/H $+\mathrm{E}$ treated juice samples exhibited the highest PC $(720.2 \pm 70.0 \mu \mathrm{g}$ GAE Eq. $/ \mathrm{mL})$ and TAA values $(5.5 \pm 1.0 \mathrm{mg}$ Trolox Eq./mL) (p < 0.05), immediately after processing. Whereas, control-2 showed only a PC value of $205.0 \pm 55.9 \mu \mathrm{g}$ GAE Eq. $/ \mathrm{mL}$ and TAA of $0.7 \pm 0.6 \mathrm{mg}$ Trolox Eq. $/ \mathrm{mL}$ by day 0 of storage. Intermediate values of both bioactive compounds were recorded for single UV-C ( $\mathrm{PC}=306.1 \pm 31.0 \mu \mathrm{g}$ GAE Eq. $/ \mathrm{mL}, \quad \mathrm{TAA}=0.7 \pm 0.3 \mathrm{mg}$ Trolox Eq. $/ \mathrm{mL}), \quad$ single $\quad \mathrm{H} \quad(\mathrm{PC}=408.0 \pm 50.0 \mu \mathrm{g} \quad \mathrm{GAE} \quad \mathrm{Eq} . / \mathrm{mL}$, $\mathrm{TAA}=2.4 \pm 0.8 \mathrm{mg} \quad$ Trolox $\quad \mathrm{Eq} . / \mathrm{mL}$ ) and UV-C/H $(\mathrm{PC}=302.1 \pm 90.1 \mu \mathrm{g}$ GAE Eq. $/ \mathrm{mL}, \quad \mathrm{TAA}=1.6 \pm 1.4 \mathrm{mg}$ Trolox Eq./mL) samples.

No differences were observed between control-2 and single UV-C, single $\mathrm{H}$ or combined $\mathrm{UV}-\mathrm{C} / \mathrm{H}$ treatments throughout storage ( $p<0.05$ ). It is important to highlight that control-2 and single treatments were only assessed for 13 days as indicated by the shelf life determined by native flora studies (Fig. 1). Whereas, UV-C/H samples were evaluated during 24 days of storage, being its PC and TAA content constant along all this period. On the other hand, UV-C/H + E samples did not exhibit changes in PC and TAA values along storage compared to day 0 , thus remaining significantly higher than control-2 and single or combined treated samples ( $p<0.05$ ) (Fig. 2a and b). This indicates that YM extract addition significantly enriched the content of these bioactive compounds in the juice blend compared to unprocessed and single or combined treated samples (Fig. 2a and b). Therefore, consumption of the proposed herbal beverage would significantly contribute to the overall polyphenol and antioxidant uptake with
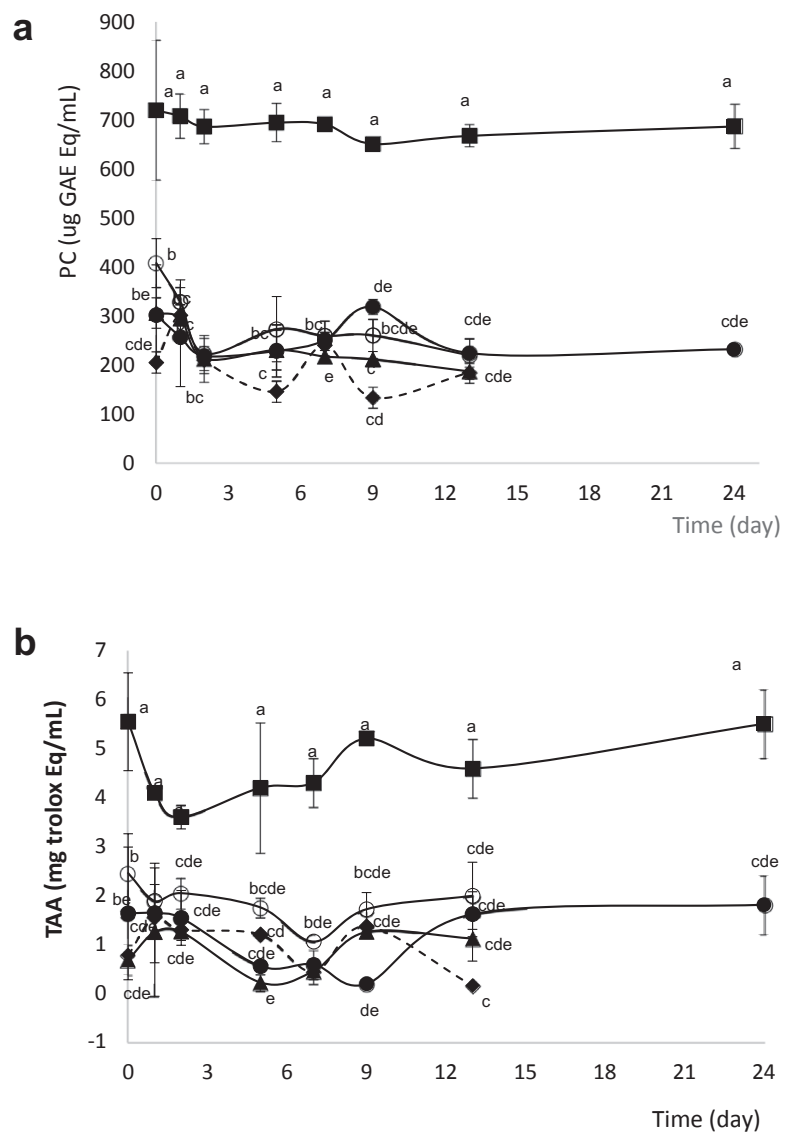

Fig. 2. Total polyphenol content (PC, $\mu \mathrm{g} \mathrm{GAE} \mathrm{Eq} / \mathrm{mL}$ ) (a), and total antioxidant activity (TAA, mg Trolox Eq/mL) (b) of untreated carrot-orange juice $(-, \downarrow)$, processed by single UV-C $(-, \mathbf{\Delta})$, single $\mathrm{H}(-, 0)$, combined UV-C/H $(-, 0)$ or UV-C/H $+\mathrm{E}(-, \square)$ along storage at $4 \pm 1{ }^{\circ} \mathrm{C}$. Different letters above the bars indicate statistically significant differences $(\mathrm{p}<0.05)$ by two-way MANOVA. Standard deviation (I).

potentially beneficial biological effects for human health.

Regarding residual polyphenol content and antioxidant activity after UV-C treatments, values reported in literature are variable depending on juice variety, settled UV-C treatment conditions and the determination method employed to detect this type of bioactive compounds. Pala and Toklucu (2013) examined total polyphenol content and antioxidant activity, by ABTS (2,20 - azinobis (3-ethylbenzo-thiazoline-6-sulfonic acid) radical, of pomegranate juice $(\mathrm{pH}=3.3,16.3$ ${ }^{\circ}$ Brix) subjected to UV-C (corrugated Teflon tube coiled around 9 UV lamps, $0.0-62.4 \mathrm{~kJ} / \mathrm{L}$ ). In agreement with the present work, UV-C treatment did not affect total phenolic and antioxidant activity values of juice samples compared to an untreated juice sample. Similarly, Caminiti, Noci, Morgan, Cronin and Lyng (2012) reported no significant changes in total phenol content and antioxidant activity in carrot-orange juice blend $\left(1: 1, \mathrm{pH}=3.8,9^{\circ} \mathrm{Brix}\right)$ treated by UV-C light $(106 \mathrm{~kJ} /$ $\mathrm{m}^{2}$ ) compared to fresh juice. Moreover, these authors reported similar total phenolic values (498-505 $\mu \mathrm{g} \mathrm{GAE} \mathrm{Eq/mL)} \mathrm{to} \mathrm{those} \mathrm{observed} \mathrm{in} \mathrm{the}$ present study (205-306 $\mu \mathrm{g}$ GAE Eq/mL) for carrot-orange juice blend control-2 and single UV-C treated samples. Additionally, Noci et al. (2008) applied static UV-C (30 $\mathrm{min}$ ) to fresh apple juice ( $\mathrm{pH}=3.7,12.8$ ${ }^{\circ} \mathrm{Brix}$ ) and reported that antioxidant capacity of juice was not affected by UV-C, while a significant decrease was observed in total phenol content compared to untreated samples. Bhat and Stamminger (2015) evaluated the total polyphenol content and total antioxidant activity by Folin Ciocalteu and DPPH, respectively, of strawberry juice $(\mathrm{pH}=3.2$, $\left.4.5{ }^{\circ} \mathrm{Brix}, 99 \mathrm{NTU}\right)$ subjected by static UV-C $\left(2.2 \mathrm{~kJ} / \mathrm{m}^{2}, 30 \mathrm{~cm}\right.$ distance from the lamp, $\left.25^{\circ} \mathrm{C}, 0-60 \mathrm{~min}\right)$. They observed a decrease in total 

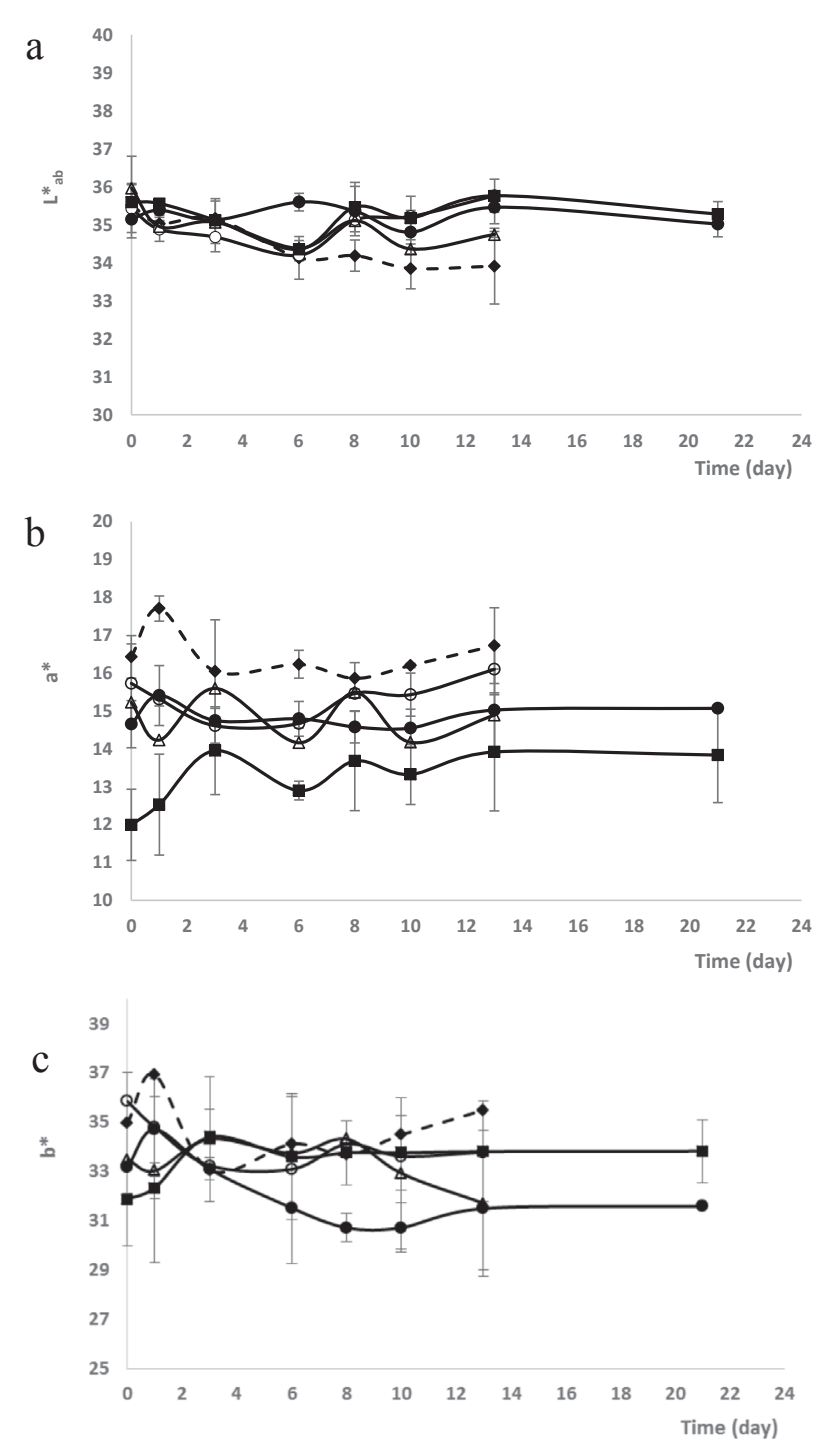

Fig. 3. Evolution of colour functions corresponding to carrot-orange juice blend control $(-, \diamond)$, or processed $(-)$ by single UV-C $(\mathrm{O})$, single $\mathrm{H}(\Delta)$, combined $\mathrm{UV}-\mathrm{C} / \mathrm{H}(\boldsymbol{)})$ and $\mathrm{UV}-\mathrm{C} / \mathrm{H}+\mathrm{E}(\square)$ along refrigerated storage. (a) Luminosity, $\mathrm{L}^{*}$; (b) a function; (c) b* function; Standard deviation (I).

phenolic compounds; whereas, total antioxidant activity was not affected compared to untreated samples after 15-min exposure. With regards to mild heat, Ferrario, Guerrero and Char (2017), evaluated the effect of total antioxidant activity by DPPH of carrot juice (pH 6.4, 11.3 ${ }^{\circ}$ Brix) subjected to mild thermal treatments $\left(56,58\right.$ and $\left.60{ }^{\circ} \mathrm{C}\right)$ at different exposure times (2, 4 and $6 \mathrm{~min}$ ) combined with acidification (pH: 4.5, 5.0 and 5.5). In contrast to the present study, in which no differences were recorded between single UV-C $\left(20^{\circ} \mathrm{C}\right)$ and UV-C/H $\left(50^{\circ} \mathrm{C}\right)$ samples compared to unprocessed juice, they observed a decrease in antioxidant activity with temperature increase. Nevertheless, temperatures assayed in that study were higher than the one evaluated in the present work. Moreover, they reported that antioxidant activity increased with acidity, and observed a maximum near the $\mathrm{pH}$ value used in the present work $(\mathrm{pH}=4.5)$.

\subsubsection{Colour, $p H$, ${ }^{\circ}$ brix and turbidity measurement}

The evolution of average CIELAB L*, a*, $b^{*}$ values corresponding to control-2 and single UV-C, single $\mathrm{H}$, combined UV-C/H and UV-C/ $\mathrm{H}+\mathrm{E}$ during storage at $4 \pm 1{ }^{\circ} \mathrm{C}$ are shown in Fig. 3. No significantly differences $(p<0.05)$ were recorded for $L^{*}, a^{*}$ and $b^{*}$ values a

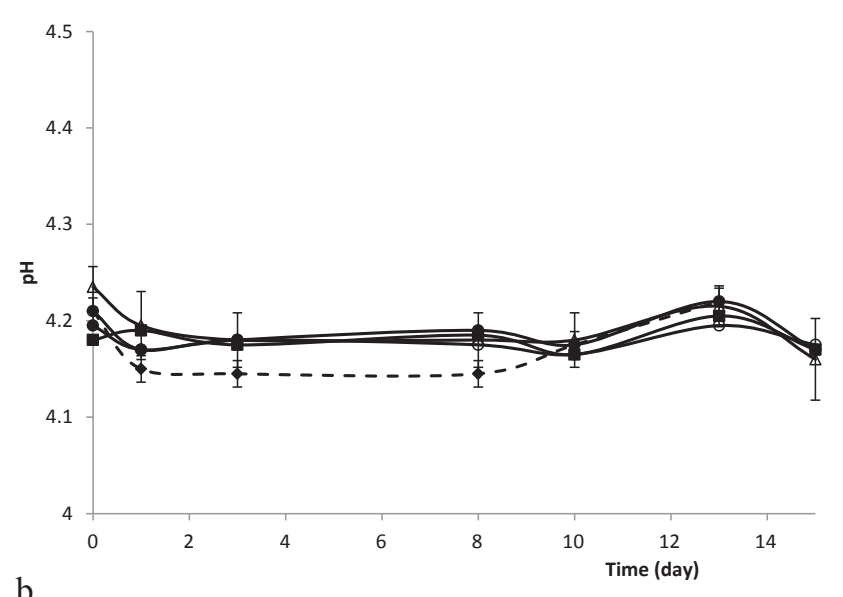

b
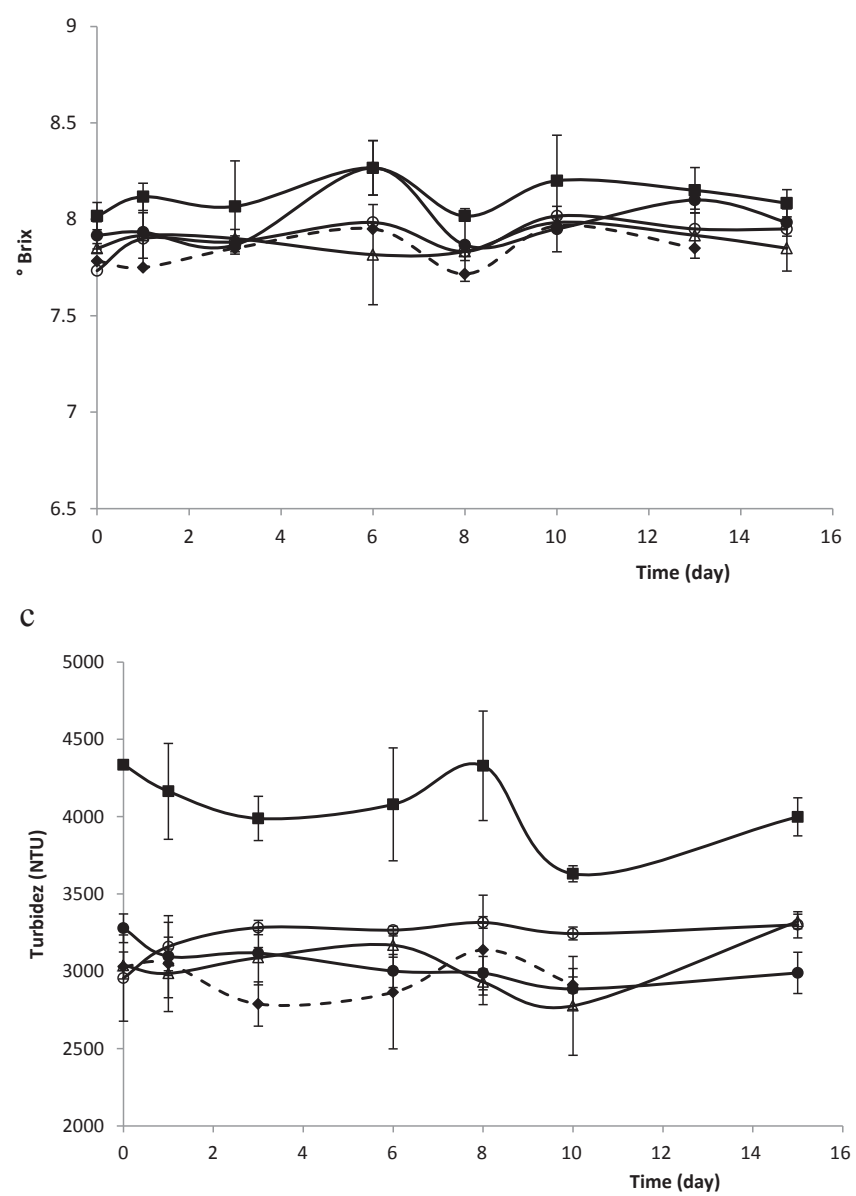

Fig. 4. Evolution of $\mathrm{pH}(\mathrm{a}),{ }^{\circ}$ Brix (b) and turbidity (c) of carrot-orange juice blend control $(-, \downarrow)$, or processed $(-)$ by single UV-C $(O)$, single $\mathrm{H}(\Delta)$, combined UV-C/H (๑) and UV-C/H + E $(\boldsymbol{\square})$ along refrigerated storage. Standard deviation (I).

immediately after processing and throughout refrigerated storage between unprocessed and single UV-C, single $\mathrm{H}$, and UV-C/H samples, indicating that treatment did not alter colour parameter values (Fig. 3). However, UV-C/H + E samples exhibited a decrease in $\mathrm{a}^{*}$ and $\mathrm{b}^{*}$ values with respect to control samples, immediately after YM addition, thus turning samples greener and more bluish and less red and yellow. Nevertheless, L ${ }^{*}$ parameter did not exhibit changes between control and all treated juices (Fig. 3).

The evolution of $\mathrm{pH},{ }^{\circ} \mathrm{Brix}$ and turbidity along refrigerated storage is 


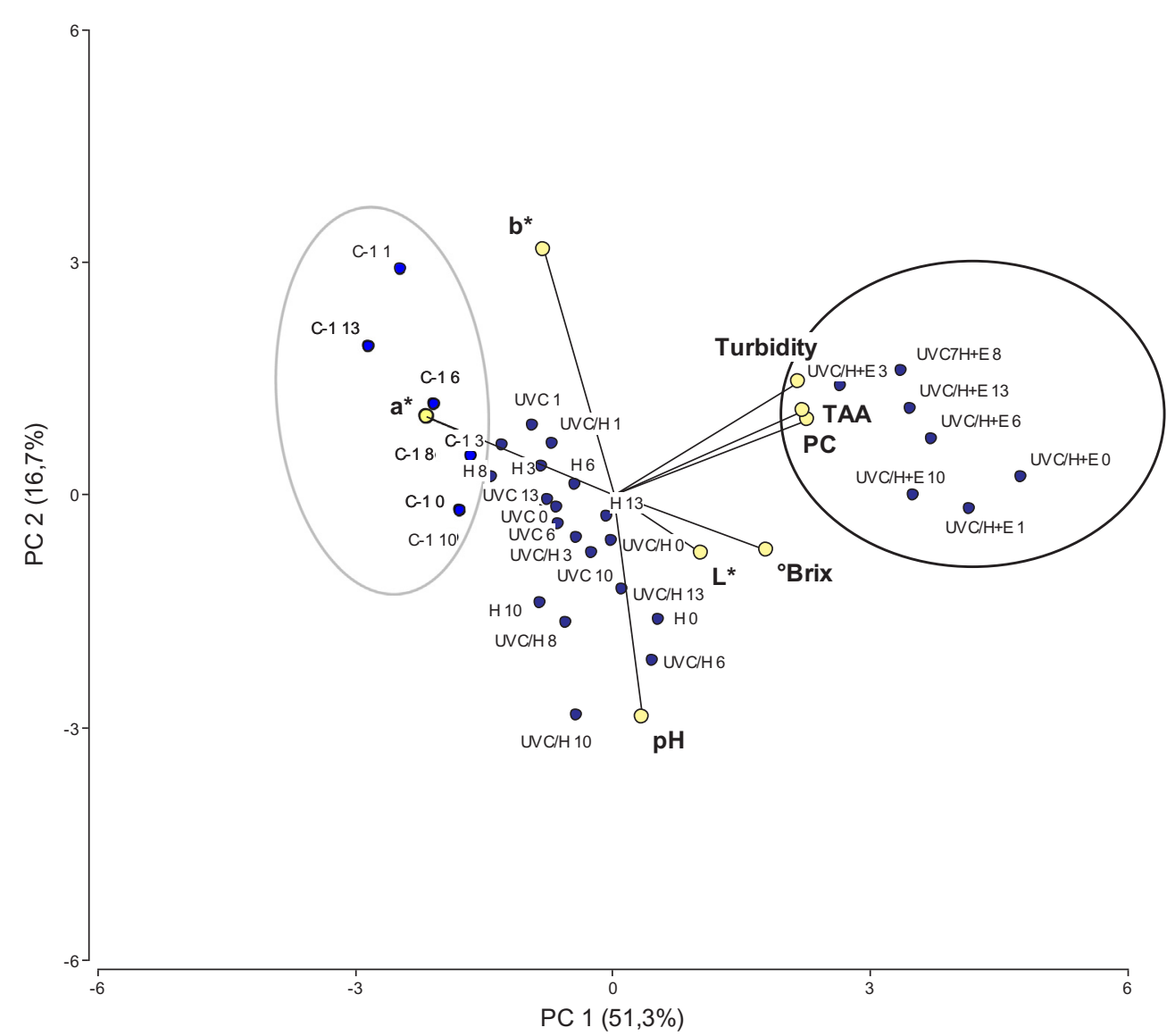

Fig. 5. Principal component analysis (PCA) bi-plot corresponding to the evolution of $\mathrm{pH}$, turbidity, ${ }^{\circ}$ Brix, and colour functions of carrot-orange juice along refrigerated storage of control (C), single UV-C (UV-C), single mild heat $(\mathrm{H})$, UV-C assisted by mild heat (UV-C/H) and combined UV-C/H with yerba mate extract (UV-C/H $+\mathrm{E}$ ) along 0 , $1,3,6,8,10$ and 13 days of storage $\left(4^{\circ} \mathrm{C}\right)$. illustrated in Fig. 4. No changes in $\mathrm{pH}$ values were observed between control-2 and all treated samples, immediately after processing and throughout refrigerated storage (Fig. 4), with $\mathrm{pH}$ values ranging between 4.18 and 4.22. In addition, no differences were recorded in ${ }^{\circ} \mathrm{Brix}$ and turbidity values between control-2 (7.6-8.1 ${ }^{\circ} \mathrm{Brix}, 2476-3224$ NTU) and single UV-C (7.6-8.0 ${ }^{\circ}$ Brix, 3016-3420 NTU) and H (7.5-8.0 ${ }^{\circ}$ Brix, 2540-3394 NTU) treatments and the combined treatment UV-C/H (7.6-8.2 ${ }^{\circ}$ Brix, 2762-3356 NTU) from the onset and throughout the whole storage (Fig. 4b and c). Nevertheless, an important increase in ${ }^{\circ}$ Brix (7.9-8.5 $\left.{ }^{\circ} \mathrm{Brix}\right)$ and turbidity (3530-4630 NTU) were observed in $\mathrm{UV}-\mathrm{C} / \mathrm{H}+\mathrm{E}$ samples, accordingly with the YM addition, which significantly increased soluble solids and suspended particles content (p < 0.05) (Fig. 4b and c).

A principal component analysis (PCA) was performed in order to assess the relationship between PC, TAA, $\mathrm{pH}$, turbidity, ${ }^{\circ} \mathrm{Brix}$ and colour functions; $\mathrm{L}^{*}, \mathrm{a}^{*}, \mathrm{~b}^{*}$ of control-2 and treated samples along storage (treatment/time). The two-dimensional representations (PCA bi-plot) are presented in Fig. 5. The CCC value was 0.9, indicating that an accurate dimension reduction was achieved with the analysis. The first two principal components $\left(\mathrm{PC}_{1}\right.$ and $\mathrm{PC}_{2}$ ) explained the $68 \%$ of the total variance. The $\mathrm{PC}_{1}$ separated turbidity, $\mathrm{PC}$ and TAA functions which were associated positively, from a ${ }^{*}$ negatively associated. On the other hand, $\mathrm{PC}_{2}$ was associated positively with $\mathrm{b}^{*}$ and negatively with $\mathrm{pH}$. This analysis showed that UV-C/H + E samples were associated to the highest turbidity, PC, TAA and ${ }^{\circ}$ Brix and lowest a ${ }^{*}$ values. Therefore, addition of YM produced an important increase in PC and TAA values, while increased the total number of suspended particles and soluble solids. Moreover, the addition of YM provoked a shift from red to greener samples. On the other hand, control-2 samples exhibited the lowest turbidity, ${ }^{\circ}$ Brix, PC and TAA values and highest a* values, indicating that unprocessed samples were the most red ones, with lower PC, TAA and suspended particles and soluble solids. With regard to single UV-C, single $\mathrm{H}$, and UV-C/H samples, they showed intermediate values of PC, TAA, a*, ${ }^{\circ}$ Brix and turbidity.

The results obtained in this study are mostly in agreement with those reported in literature as scarce to no changes in colour, $\mathrm{pH}$, ${ }^{\circ} \mathrm{Brix}$ and scarce to moderate changes in turbidity were provoked by UV-C treatments. In accordance, various studies have shown that UV-C irradiation is unable to inactivate pectin methyl esterase (PME) enzyme in fruit juices; thus provoking an increase in turbidity. For example, Tran and Farid (2004) reported that UV-C treatment was able to inactivate only $5 \%$ of PME enzyme and did not prevent the cloudiness of the orange juice after UV treatment $\left(0.73 \mathrm{~kJ} / \mathrm{m}^{2} \mathrm{UV}\right.$ dose). Caminiti et al. (2012) evaluated changes on $\mathrm{pH},{ }^{\circ} \mathrm{Brix}$ and colour of carrot-orange juice blend $\left(1: 1, \mathrm{pH}=3.8,9^{\circ}\right.$ Brix $)$ treated by single UV-C $\left(106 \mathrm{~kJ} / \mathrm{m}^{2}\right)$, and in accordance to the present work, they did not observe changes in $\mathrm{pH}$, ${ }^{\circ}$ Brix, $\mathrm{L}^{*}, \mathrm{a}^{*}$ and $\mathrm{b}^{*}$ parameters after UV-C processing compared to untreated juice samples. In addition, Kaya, Yildiz and Ünlütürk (2015) studied $\mathrm{pH},{ }^{\circ} \mathrm{Brix}$, turbidity and colour changes of lemon-melon juice blend $(\mathrm{pH}=3.9)$ after UV-C $(2.5 \mathrm{~kJ} / \mathrm{L})$ processing, applying a very similar UV-C dose compared to that applied in the present work $(2 \mathrm{~kJ} / \mathrm{L})$. Neither $\mathrm{pH}$ nor $\mathrm{L}^{*}$ and $\mathrm{a}^{*}$ colour parameters were affected after UV-C treatment; whereas, $b^{*}$ value was significantly reduced. In accordance to the present work, an increase in turbidity was observed after UV-C treatment compared to untreated juice samples.

\subsection{Sensory studies}

\subsubsection{Consumer field test}

Carrot-orange juice blend samples processed by UV-C/H + E were evaluated by using a consumer field test to determine the overall liking and consumer's opinion about some relevant sensory juice attributes. The overall acceptability of samples averaged 6.1 in the 9-point hedonic scale, which corresponded to the category "like slightly" in the used 
scale. However, by applying cluster analysis for obtaining segmentation of consumer groups' preferences, two clusters emerged: cluster 1 (C1), with 40 consumers, encompassing categories 1-4 in the 9-point hedonic scale, and cluster 2 (C2), with 46 consumers, including categories 5-9 (data not shown). The CCC value obtained was 0.80 , indicating that a good fit was achieved by this analysis. C2 showed a marked interest in the product, exhibiting an averaged overall liking of 7.0 in the 9-point hedonic scale (corresponding to the category "like it moderately"). They also significantly perceived bitterness $(2.9 \pm 1.1)$ and YM aroma (3.6 \pm 0.9$)$, closer to the just right value $(2.5)$ than C1 (bitterness $=3.5 \pm 1.4, \mathrm{YM}$ aroma $=4.1 \pm 0.8)(\mathrm{p}<0.05)$. Therefore, the carrot-orange juice processed by UV-C/H $+\mathrm{E}$ exhibited a maximal appeal to a group of consumers, in agreement with the segmentation approach, which manufacturers have largely embraced in recent years. This approach considers that constructing different products to groups of consumers who display different tastes will exhibit more acceptability than developing a unique product to the entire pool of users (Lawless, 2013a,b). Open-ended questions revealed that herbal taste was mostly highlighted by the consumers.

A principal component analysis (PCA) was performed in order to assess the relationship between scores corresponding to the hedonic scale and $\%$ of responses in bitterness, sour, herbal aroma, herbal taste and juice body. The two-dimensional representations (PCA bi-plot) are presented in Supplementary material 1 . The CCC value was 0.94 , indicating that an accurate dimension reduction was achieved with the analysis. The first two principal components $\left(\mathrm{PC}_{1}(49.2 \%)\right.$ and $\mathrm{PC}_{2}$ (30.1\%)) explained the $79.3 \%$ of the total variance (Supplementary material 1). The $\mathrm{PC}_{1}$ was positively associated to bitterness, sour and herbal aroma. On the other hand, $\mathrm{PC}_{2}$ showed positive association with herbal taste. This analysis showed that C1 (scores from 1 to 4) was associated with extreme sour tasting, bitterness, herbal aroma and intense herbal taste, while C2 (scores from 5 to 9) was associated with optimal sour tasting and herbal aroma, and adequate bitterness and herbal taste.

Supplementary data associated with this article can be found, in the online version, at https://doi.org/10.1016/j.foodchem.2018.06.149.

Orjuela Palacio, Zamora and Lanari (2014) evaluated the overall acceptance of a high-polyphenol yerba mate/black currant beverage, made by mixing juice of ripe black currant berries and extract of yerba mate obtained by a traditional extraction $\left(100^{\circ} \mathrm{C}, 15 \mathrm{~min}\right)(60: 20)$ with or without sweeteners. They reported that although mean values of the acceptability was 5.6 for the beverage with sweetener considering all panelists, $57 \%$ of consumers evaluated the beverage with scores in the range from 6 to 9 on the 9-point hedonic scale. These result reveals, in agreement with the present work, the existence of a particular group of consumers interested in yerba mate beverages.

With regard to sensory analysis of juice blends, Jan and Masih (2012) evaluated the overall acceptance of pineapple-carrot-orange juice blend $(60: 10: 30, \mathrm{pH}=4.2)$ pasteurized at $90^{\circ} \mathrm{C}$ for $25 \mathrm{~s}$, and reported an 8 score in a 9-point hedonic scale. The higher score obtained in this study compared to the one obtained in the present work may be attributed to the high proportion of pineapple juice and low carrot juice content and the absence of astringent compounds found in yerba mate, which cause higher sweetness perception and lower bitterness, respectively, compared to the UV-C/H + E sample.

\subsubsection{Check-all-that-apply (CATA) question}

Consumers used between 1 and 10 terms to describe juice samples in the check-all-that-apply question. The most frequently used terms were herbal aroma, herbal taste, strong colour, natural taste, intense taste. On the other hand, the least used terms were not fruity, too much orange taste, artificial taste, with aftertaste, cooked taste.

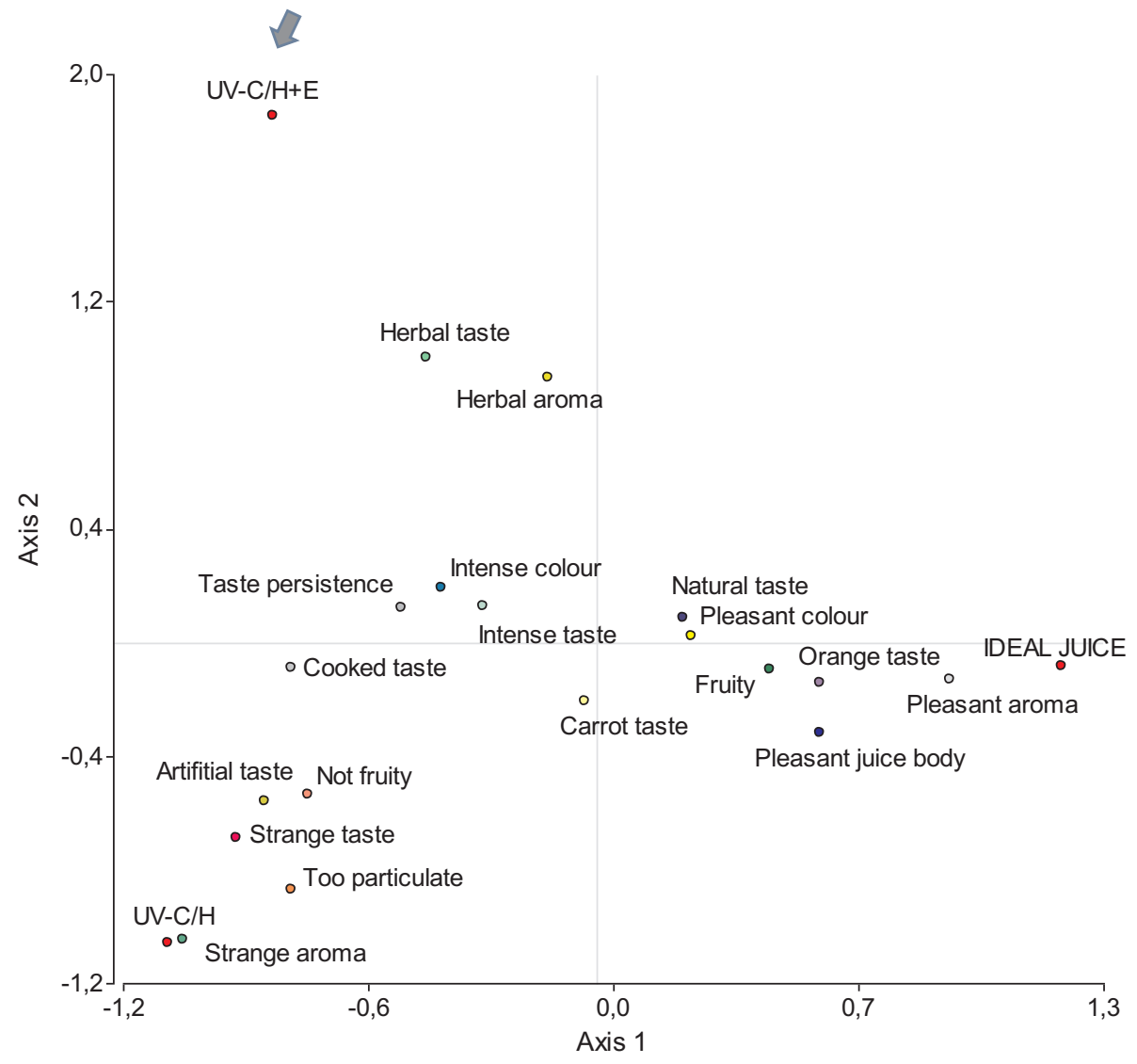

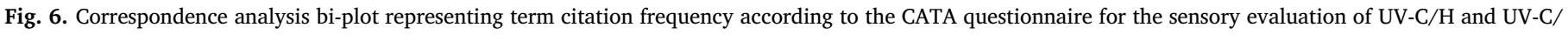
$\mathrm{H}+\mathrm{E}$ juice blend samples as well as an ideal juice sample defined by consumers from a checklist included in the CATA questionnaire. 
A correspondence analysis (CA) was performed for sensory descriptors, as explained in materials and methods item 2.7.2 and is displayed in Fig. 6. The first and second dimension of the CA calculated from CATA counts represented $35.8 \%$ and $63.6 \%$ of experimental data variance, respectively. UV-C/H + E juice exhibited negative and positive values for axes 1 and 2, respectively, and was described by consumers as intense taste, herbal taste, herbal aroma, strong colour, and taste persistence. Whereas, UV-C/H sample showed negative values for both axis, and was described as cooked taste, artificial taste, strange aroma, not fruity, with carrot taste, too particulate. Whilst, the ideal juice was described as fruity, with orange taste and pleasant juice body and pleasant aroma. Therefore, the comparison between real juice samples with an ideal beverage defined by consumers was suitable to identify specific improvements that might be addressed to the studied samples. In particular, consumers would ideally have expected a stronger orange taste and weaker herbal taste and aroma than those they perceived in the UV$\mathrm{C} / \mathrm{H}+\mathrm{E}$ sample.

Additionally, the frequency at which consumers described processed juices by non-sensory descriptors were analyzed by $\chi^{2}$ test. The most mentioned non-sensory descriptor characterizing UV-C/H and UV-C/ $\mathrm{H}+\mathrm{E}$ samples was would consume occasionally. However, there were no differences between the UV-C/H and UV-C/H + E samples regarding any of the non-sensory descriptors analyzed.

\section{Conclusions}

A novel functional carrot-orange juice processed by UV-C light and assisted by mild heat and added with yerba mate extract was developed, which could represent a relevant contribution to the diary polyphenol and antioxidant intake. Considering the high turbidity of this blend, the use of UV-C processing under hurdle approach, would represent a promising alternative for native flora inactivation along refrigerated storage, preserving colour, $\mathrm{pH}$, turbidity, polyphenol content and antioxidant activity of a high turbidity juice blend, with a slight change of ${ }^{\circ}$ Brix. The addition of yerba mate provoked an important increase in total polyphenol content and total antioxidant activity of carrot-orange juice blend. Besides, yerba mate addition produced a slight change in colour of the juice, diminishing red and yellow while turning samples greener and more bluish. Moreover, a slight increase in soluble solids and turbidity was also observed after yerba mate addition. The segmentation approach revealed that a group of consumers showed a very strong interest in the bitter taste and herbal aroma of the product. Nevertheless, CATA question revealed, through the comparison of real samples with an ideal beverage, that certain changes should be introduced in the UV-C assisted by mild heat and yerba mate addition sample in favour of stronger orange and fruity taste, pleasant juice body and pleasant aroma.

The consumer profiling techniques used in this study, field test and CATA question, provided complementary descriptive sensory information about this juice preserved by UV-C assisted by mild heat and YM addition. Moreover, CATA question was a powerful product design tool for measuring how distant the UV-C/H + E processed samples were from an ideal juice blend. Nevertheless, further studies focused on further extending juice shelf life and evaluating other quality parameters such as relevant enzymes' activities, carotene, and ascorbic acid contents will be conducted in the near future in order to have a more finished approach to the proposed technology.

\section{Acknowledgements}

The authors would like to acknowledge the financial support from Universidad de Buenos Aires (UBACYT 2017-2020 Project), Consejo Nacional de Investigaciones Científicas y Técnicas (CONICET) (2012289 Project), Instituto Nacional de la Yerba Mate (INYM) (N 69, Res. 310/2015) and Agencia Nacional de Promoción Científica y Tecnológica (ANPCyT) (2015-0401 Project) of Argentina and from
Banco Interamericano de Desarrollo.

\section{References}

Baysal, A., Molva, C., \& Unluturk, S. (2013). UV-C light inactivation and modeling kinetics of Alicyclobacillus acidoterrestris spores in white grape and apple juices. International Journal of Food Microbiology, 166, 494-498.

Bhat, R., \& Stamminger, R. (2015). Impact of ultraviolet radiation treatments on the physicochemical properties, antioxidants, enzyme activity and microbial load in freshly prepared hand pressed strawberry juice. Revista de Agroquímica y Tecnología de Alimentos, 21, 354-363.

Burris, K., Higginbotham, K., \& Neal Stewart, C., Jr (2015). Aqueous extracts of yerba mate as bactericidal agents against methicillin-resistant Staphylococcus aureus in a microbiological medium and ground beef mixtures. Food Control, 50, 748-753.

Caminiti, I., Noci, F., Morgan, D., Cronin, D., \& Lyng, J. (2012). The effect of pulsed electric fields, ultraviolet light or high intensity light pulses in combination with manothermosonication on selected physico-chemical and sensory attributes of an orange and carrot juice blend. Food and Bioproducts Processing, 90, 442-448.

Char, C., Guerrero, S., \& Alzamora, S. M. (2010). Use of high-intensity ultrasound and UV$\mathrm{C}$ light to inactivate some microorganisms in fruit juices. Food and Bioprocess Technology, 3, 797-803.

Chau, C., Chen, C., \& Lee, M. (2004). Comparison of the characteristics, functional properties, and in vitro hypoglycemic effects of various carrot insoluble fiber-rich fractions. LWT-Food Science and Technology, 37, 155-160.

Chia, S., Rosnah, S., Noranizan, M., \& Wan, R. (2012). The effect of storage on the quality attributes of ultraviolet-irradiated and thermally pasteurized pineapple juices. International Food Research Journal, 19, 1001-1010.

Cortés, C., Esteve, M., \& Frígola, A. (2008). Color of orange juice treated by high intensity pulsed electric fields during refrigerated storage and comparison with pasteurized juice. Food Control, 19, 151-158.

De Carvalho, J., Maia, G., \& De Figueredo, R. (2007). Development of a blended nonalcoholic beverage composed of coconut water and cashew apple juice containing caffeine. Journal of Food Quality, 30, 664-681.

Dias, J. (2012). Major classes of phytonutriceuticals in vegetables and health benefits: A review. Journal of Nutritional Therapeutics, 1, 31-62.

Feng, M., Ghafoor, K., Seo, B., Yang, K., \& Park, J. (2013). Effects of ultraviolet-C treatment in Teflon ${ }^{\oplus}$-coil on microbial populations and physico-chemical characteristics of watermelon juice. Innovative Food Science and Emerging Technologies, 19 133-139.

Ferrario, M., Guerrero, S., \& Char, C. (2017). Optimization of minimal processing variables to preserve the functional quality and colour of carrot juice by means of the response surface methodology. International Journal of Food Science and Technology, $52,864-871$.

García Carrillo, M., Ferrario, M., \& Guerrero, S. (2017b). Estudio del efecto del procesamiento con luz UV-C asistida por temperatura moderada de un jugo frutihortícola de alta turbidez en la inactivación microbiana. Poster session at XI Congreso IberoAmericano de Ingeniería de Alimentos (CIBIA XI), Valparaíso, Chile.

García Carrillo, M., Ferrario, M., \& Guerrero, S. (2017a). Study of the inactivation of some microorganisms in turbid carrot-orange juice blend processed by ultraviolet light assisted by mild heat treatment. Journal of Food Engineering, 212, 213-225.

Gayán, E., Serrano, M., Monfort, S., Álvarez, I., \& Condón, S. (2012). Combining ultraviolet light and mild temperatures for the inactivation of Escherichia coli in orange juice. Journal of Food Engineering, 113, 598-605.

Guerrero, S., Alzamora, S., \& Ferrario, M. (2016). The use of pulsed light in a hurdle preservation strategy. In G. Pataro, \& J. Lyng (Eds.). High intensity pulsed light in processing and preservation of foods (pp. 205-228). New York: NOVA Publishers.

Guerrero, S., Ferrario, M., Schenk, M., \& Garcia Carrillo, M. (2017). Hurdle technology using ultrasound for food preservation. In Daniela Bermudez-Aguirre (Ed.). Ultrasound: Advances for food processing and preservation (pp. 39-99). Academic Press.

Gutiérrez, D., Char, C., Escalona, V., Chaves, A., \& Rodriguez, S. (2015). Application of UV-C radiation in the conservation of minimally processed rocket (Eruca sativa Mill.). Journal of Food Processing and Preservation, 39, 3117-3127.

HPA (Health Protection Agency) (2009). Guidelines for Assessing the Microbiological Safety of Ready-to-Eat Foods. London. URL < https://www.gov.uk/government/ uploads/system/uploads/attachment_data/file/363146/Guidelines_for_assessing_ the_microbiological_safety_of_ready-to-eat_foods_on_the_market.pdf $>$.

ISO (1988). Sensory analysis: General guidance for the design of test rooms, ISO 8589. Geneva, Switzerland: International Organization for standardization.

Jan, A., \& Masih, E. (2012). Development and quality evaluation of pineapple juice blend with carrot and orange juice. International Journal of Scientific and Research Publications, 2, 1-8.

Kaya, Z., Yıldız, S., \& Ünlütürk, S. (2015). Effect of UV-C irradiation and heat treatment on the shelf life stability of a lemon-melon juice blend: Multivariate statistical approach. Journal of Food Processing and Preservation, 39, 230-239.

Koutchma, T. (2009). Advances in ultraviolet light technology for non-thermal processing of liquid foods. Food and Bioprocess Technology, 2, 138-155.

Lawless, H. T. (2013a). Frequency count data situations: Open ends, CATA. In H. T. Lawless (Ed.). Quantitative sensory analysis: Psychophysics, models and intelligent design (pp. 416). Oxford: Wiley Blackwell.

Lawless, H. (2013b). Segmentation. In H. Lawless (Ed.). Quantitative sensory analysis. Psychophysics, models and intelligent design (pp. 323-338). Oxford: Wiley Blackwell.

Lawless, H., \& Heymann, H. (2010). Consumer field tests and questionnaire design. In D. R. Heldman (Ed.). Sensory evaluation of food. Principles and practices (pp. 349-378). New York: Springer.

Leatherhead Food Research. (2013). Future directions for the global functional foods 
market. URL < http://www.leatherheadfood.com/market > Accesed 09.01.2018.

Mathews, K. (2006). Microorganisms associated with fruits and vegetables. In K. R.

Matthews (Ed.). Microbiology of fresh produce. Washington DC USA: American Society for Microbiology Press.

Noci, F., Riener, J., Walkling-Ribeiro, M., Cronin, D., Morgan, D., \& Lyng, J. (2008). Ultraviolet irradiation and pulsed electric fields (PEF) in a hurdle strategy for the preservation of fresh apple juice. Journal of Food Engineering, 85, 141-146.

Orjuela-Palacio, J., Zamora, M., \& Lanari, M. (2014). Consumers' acceptance of a highpolyphenol yerba mate/black currant beverage: Effect of repeated tasting. Food Research International, 57, 26-33.

Pala, Ç., \& Toklucu, A. (2013). Microbial, physicochemical and sensory properties of UVC processed orange juice and its microbial stability during refrigerated storage. LWTFood Science and Technology, 50, 426-431.

Polydera, A., Stoforos, N., \& Taoukis, P. (2003). Comparative shelf life study and vitamin $\mathrm{C}$ loss kinetics in pasteurized and high pressure processed reconstituted orange juice. Journal of Food Engineering, 60, 21-29.

Rahn, R. (1997). Potassium iodide as a chemical actinometer for $254 \mathrm{~nm}$ radiation: Use of iodate as an electron scavenger. Photochemistry and Photobiology, 66, 450-455.

Ross, A., Griffiths, M., Mittal, G., \& Deeth, H. (2003). Combining nonthermal technologies to control foodborne microorganisms. International Journal of Food Microbiology, 89, $125-138$.
Schenk, M., García Loredo, A., Raffellini, S., Alzamora, S. M., \& Guerrero, S. (2012). The effect of UV-C in combination with $\mathrm{H} 2 \mathrm{O} 2$ treatments on microbial response and quality parameters of fresh cut pear discs. International Journal of Food Science and Technology, 47, 1842-1851.

Seljåsen, R., Kristensen, H., Lauridsen, C., Wyss, G., Kretzschmar, U., Birlouez-Aragone, I. \& Kahl, J. (2013). Quality of carrots as affected by pre- and postharvest factors and processing. Journal of the Science of Food and Agriculture, 93, 2611-2626.

Shah, N., Shamsudin, R., Abdul Rahman, R., \& Adzahan, N. (2016). Fruit juice production using ultraviolet pasteurization: A review. Beverages, 2, 22. https://doi.org/10.3390/ beverages 2030022

Singleton, V., Orthofer, R., Lamuela-Raventós, R., \& Lester, P. (1999). Analysis of total phenols and other oxidation substrates and antioxidants by means of Folin-Ciocalteu reagent. Methods in Enzymoly, 299, 152-178.

Tamasi, O., Filip, R., Ferraro, G., \& Calviño, A. (2007). Total polyphenol content and perceived astringency of yerba mate "Ilex paraguariensis" infusions. Journal of Sensory Studies, 22, 653-664.

Tan, S. (2012). Effect of combining mild heat with ultraviolet treatment on quality of green guava juice. Bachelor's Thesis, University Putra Malaysia, Serdang, Selangor, Malaysia.

Tran, M., \& Farid, M. (2004). Ultraviolet treatment of orange juice. Innovative Food Science and Emerging Technologies, 5, 495-502. 